\title{
Using time-lapse gravity for groundwater model calibration: An application to alluvial
} aquifer storage

Christiansen, Lars; Binning, Philip John; Rosbjerg, Dan; Bauer-Gottwein, Peter; Andersen, Ole Baltazar

Published in:

Water Resources Research

Link to article, DOI:

10.1029/2010WR009859

Publication date:

2011

Document Version

Publisher's PDF, also known as Version of record

Link back to DTU Orbit

Citation (APA):

Christiansen, L., Binning, P. J., Rosbjerg, D., Bauer-Gottwein, P., \& Andersen, O. B. (2011). Using time-lapse gravity for groundwater model calibration: An application to alluvial aquifer storage. Water Resources Research, 47(6), [W06503]. https://doi.org/10.1029/2010WR009859

\section{General rights}

Copyright and moral rights for the publications made accessible in the public portal are retained by the authors and/or other copyright owners and it is a condition of accessing publications that users recognise and abide by the legal requirements associated with these rights.

- Users may download and print one copy of any publication from the public portal for the purpose of private study or research.

- You may not further distribute the material or use it for any profit-making activity or commercial gain

- You may freely distribute the URL identifying the publication in the public portal 


\title{
Using time-lapse gravity for groundwater model calibration: An application to alluvial aquifer storage
}

\author{
L. Christiansen, ${ }^{1}$ P. J. Binning, ${ }^{1}$ D. Rosbjerg, ${ }^{1}$ O. B. Andersen, ${ }^{2}$ and P. Bauer-Gottwein ${ }^{1}$ \\ Received 9 August 2010; revised 9 March 2011; accepted 17 March 2011; published 8 June 2011. \\ [1] The estimation of hydrological model parameters by calibration to field data is a \\ critical step in the modeling process. However, calibration often fails because of parameter \\ correlation. Here it is shown that time-lapse gravity data can be combined with hydraulic \\ head data in a coupled hydrogeophysical inversion to decrease parameter correlation in \\ groundwater models. This is demonstrated for a model of riverbank infiltration where \\ combined inversion successfully constrains hydraulic conductivity and specific yield in \\ both an analytical and a numerical groundwater model. A sensitivity study shows that \\ time-lapse gravity data are especially useful to constrain specific yield. Furthermore, we \\ demonstrate that evapotranspiration, and riverbed conductance are better constrained by \\ coupled inversion to gravity and head data than to head data alone. When estimating the \\ four parameters simultaneously, the six correlation coefficients were reduced from unity \\ when only head data were employed to significantly lower values when gravity and head \\ data were combined. Our analysis reveals that the estimated parameter values are not very \\ sensitive to the choice of weighting between head and gravity data over a large interval \\ of relative weights.
}

Citation: Christiansen, L., P. J. Binning, D. Rosbjerg, O. B. Andersen, and P. Bauer-Gottwein (2011), Using time-lapse gravity for groundwater model calibration: An application to alluvial aquifer storage, Water Resour. Res., 47, W06503, doi:10.1029/2010WR009859.

\section{Introduction}

[2] Field data are crucial in hydrological modeling in order to calibrate and test a proposed model. Geophysical time-lapse data provide a noninvasive or minimally invasive way to obtain knowledge about the content and movement of water and contaminants in the subsurface that, in turn, are a function of the hydraulic properties of the soil. Several studies have used electrical resistivity [Zhou et al., 2001; Michot et al., 2003; Reedy and Scanlon, 2003; Samouelian et al., 2005; Bauer et al., 2006a; Uhlenbrook and Wenninger, 2006; Schwartz et al., 2008; Cassiani et al., 2009] and/or electromagnetic [Hagrey and Müller, 2000; Knight, 2001; Huisman et al., 2003; Looms et al., 2008a, 2008b; BauerGottwein et al., 2010] data to test hydrological models. A common issue in such studies is the need for a petrophysical relationship to link the measured quantity (electric resistivity or relative permittivity) to the quantity of interest (e.g., soil water content). This introduces an extra source of uncertainty in the use of these data types, as the relationships are usually only valid under certain conditions, e.g., sandy soils with low clay content [Topp et al., 1980], or require formation specific constants to be known [Archie, 1942].

[3] Time-lapse gravity data are a direct measure of the change in mass. If other contributing sources can be estimated, the data provide a measure of the change in soil water content. Thus, time-lapse gravity can be directly

\footnotetext{
${ }^{1}$ DTU Environment, Kongens Lyngby, Denmark

${ }^{2}$ DTU Space, Copenhagen, Denmark.
}

Copyright 2011 by the American Geophysical Union. 0043-1397/11/2010WR009859 coupled to the change of hydrological state variables, without using a petrophysical relationship. The use of timelapse gravity data in hydrology was first demonstrated by Montgomery [1971], who estimated specific yield through groundwater level variations in boreholes and relative gravity measurements. The change in water table was approximated by a Bouguer slab, an infinite horizontal slab of water. Later authors have used gravimetry to measure production-induced drawdown [Pool and Eychaner, 1995; Pool, 2008; Gehman et al., 2009], injection mounds [Howle et al., 2003; Chapman et al., 2008], and more complex systems with water abstraction, irrigation, and precipitation [Gettings et al., 2008]. Storage changes were estimated by Jacob et al. [2008, 2009] for karst formations, by Davis et al. [2008] for water injection into an abandoned mine, by Crook et al. [2008] below paved urban areas, and by Pfeffer et al. [2011] for an unconfined aquifer connected to a pond for which the storage level is controlled by a monsoon. The methods applied in the cited literature vary from the simple Bouguer slab approximation to full 3-D geophysical inversion for the density contrast created by the changing water content, with the target parameter being either specific yield or the hydraulic conductivity. A recent example of the use of 3-D forward calculation of time-lapse gravity from a hydrological model was shown by Naujoks et al. [2010], who evaluated seven different versions of the hydrological model made by Krause et al. [2009]. Two out of the seven models were shown to match gravity data to a reasonable degree.

[4] The assumption of a horizontal water table is computationally convenient [e.g., Leirião et al., 2009; Christiansen et al., 2011] but leads to wrong parameter estimates for more 
complicated water distributions such as drawdown cones around production wells and infiltration mounds [e.g., Pool, 2008]. Three-dimensional inversion, on the other hand, requires a large number of geophysical model parameters to be estimated, increasing the required amount of gravity data in order to constrain the inversion. By letting the physics of the hydrological model govern the shape of the water body in the geophysical inversion, the only parameters required are those of the hydrological model. This approach is termed coupled hydrogeophysical inversion [Ferré et al., 2009; Hinnell et al., 2010] and has been used in an increasing number of studies [e.g., Kowalsky et al., 2004; Rucker and Ferré, 2004; Looms et al., 2008a; Rings et al., 2010]. The use of gravity data for a coupled hydrogeophysical inversion was demonstrated by Blainey et al. [2007] in a synthetic study. They simulated a pumping test and demonstrated improved estimates of specific yield and the hydraulic conductivity for the combination of drawdown and gravity data and compared their approach to the use of drawdown data alone. Coupled hydrogeophysical inversion requires a forward calculation from the water distribution to a gravity signal [see, e.g., Damiata and Lee, 2006; Hasan et al., 2008; Creutzfeldt et al., 2008; Leirião et al., 2009].

[5] Here time-lapse relative gravity data are employed to constrain the calibration of a riverbank storage model in combination with hydraulic head data. The four parameters are horizontal hydraulic conductivity $\left(K_{h}\right)$, specific yield $\left(S_{y}\right)$, riverbed conductance $\left(C_{r}\right)$, and evapotranspiration (ET). Riverbank storage provides an important source of groundwater in river systems with large (meters) variations in water level. Examples of efforts to model riverbank storage systems include the planning of new well fields [Department of Water Affairs, 2004], ecosystem understanding [Wolski and Savenije, 2006], and monitoring of pollution migration to a river [Ma et al., 2010].

[6] In this paper an overview of the field site and the collected data are presented. Two models of recharge into a riverbank are employed: an analytical model, which illustrates the fundamental problem in estimating both $K_{h}$ and $S_{y}$ at the same time, and a numerical model, which includes the additional parameters $C_{r}$ and ET. We show that the introduction of gravity data decreases the magnitude of all parameter correlation coefficients and allows the estimation of up to four parameters. This is the first time coupled hydrogeophysical inversion of gravity and head data has been performed using field data.

\section{Methods}

\subsection{Site Description}

[7] The Matsibe River is a part of the Okavango Delta in northern Botswana. The downstream section is ephemeral and undergoes an annual drying and flooding cycle, which results in variations of several meters in the groundwater table in the surrounding riverbanks. Local precipitation falls during the wet season (November-March), with an average annual rainfall of $450 \mathrm{~mm}$, as measured in Maun south of the delta [Milzow et al., 2009]. The flood water falls as rain in Angola in the upper part of the river basin and arrives to the Okavango Delta in the dry season. It provides an important source of water during this period and is essential for supplying the population in and around the delta and the rich flora and fauna in the semiarid area.
[8] We chose a site in the downstream end of the Matsibe River (latitude, $-20.145308^{\circ}$; longitude, $23.059100^{\circ}$ ) where the subsurface consists of sand with interlayered layers of sandy clay to clayey sand, a common setting for the Okavango Alluvial Fan [Milzow et al., 2009]. At the time of the measurements, the initial water table was about 2-4 m below the surface and placed above the topmost clay layer, forming an unconfined aquifer. Head changes in a nearby borehole (BH8274, Department of Water Affairs, Botswana) screened below the topmost clay layer from 46.3 to $55 \mathrm{~m}$ indicated that the lower aquifers are semiconfined or leaky.

[9] Net evapotranspiration in the Okavango Delta is largely vegetation driven and varies from $3-3.3 \mathrm{~mm} \mathrm{~d}^{-1}$ in June/July to a maximum of $8.3 \mathrm{~mm} \mathrm{~d}^{-1}$ in October [Ramberg et al., 2006]. The field site stretches over $400 \mathrm{~m}$ perpendicular to the riverbed on one side of the river. It varies from the unvegetated and sandy central riverbed $(0-$ $30 \mathrm{~m}$ ), over a grass vegetated floodplain $(30-260 \mathrm{~m})$, to riparian forest at higher elevations $(260-400 \mathrm{~m})$. As the river rises, it spreads over the floodplain, which is covered by an organic topsoil.

\subsection{Data Collection}

[10] A transect, transect 1, was established perpendicular to the Matsibe River. Four different types of data were collected: topographic data, hydraulic head variations, river stage, and changes in gravity with time. Data were collected over a total of 4 months, with the river flooding over the last 38 days. All temporal data were gathered during July and August 2008, and for the analysis, variations within a given day are not considered: each measurement is assumed to occur at 12 noon. For the correction of the gravity data, the actual time of measurement was used (see section 2.2.3).

\subsubsection{Topographic Measurements}

[11] Surface height measurements served to define the topographic profile for the model and for topography correction of the head data. Furthermore, the gravity data are very sensitive to height changes of individual gravity stations relative to the reference station (see section 2.2.3).

[12] The lowest point in the riverbed along the transect was defined as the zero level, all other points were measured relative to this datum (see Figure 1). The Leica TCR 303 theodolite used in the campaign has a reported uncertainty of $0.003 \mathrm{~m}$. Because of vegetation and increased instrument uncertainty over longer lines of sight, the profile was measured in six partially overlapping pieces, which gave $0.07 \mathrm{~m}$ accumulated uncertainty on the difference between the two end points on the transect. Borehole caps and gravity stations were used as stable points, with provisional intermediate points of wooden pegs. Surveying showed that the topographic profile of the flat riverbank has a maximum height difference of only $1.94 \mathrm{~m}$ over about $300 \mathrm{~m}$.

[13] The height of the gravity stations was measured before and after flood arrival. This was done relative to fixed points in the form of screws placed slightly above ground level in various trees. Height changes varied less than twice the standard deviation $(0.006 \mathrm{~m})$ of the instrument and were considered negligible.

\subsubsection{Heads and River Stage}

[14] Heads were measured before and during the flooding of the river in 11 boreholes, which were hand augered and bailed to $0.5-2 \mathrm{~m}$ below the initial water table and fitted 


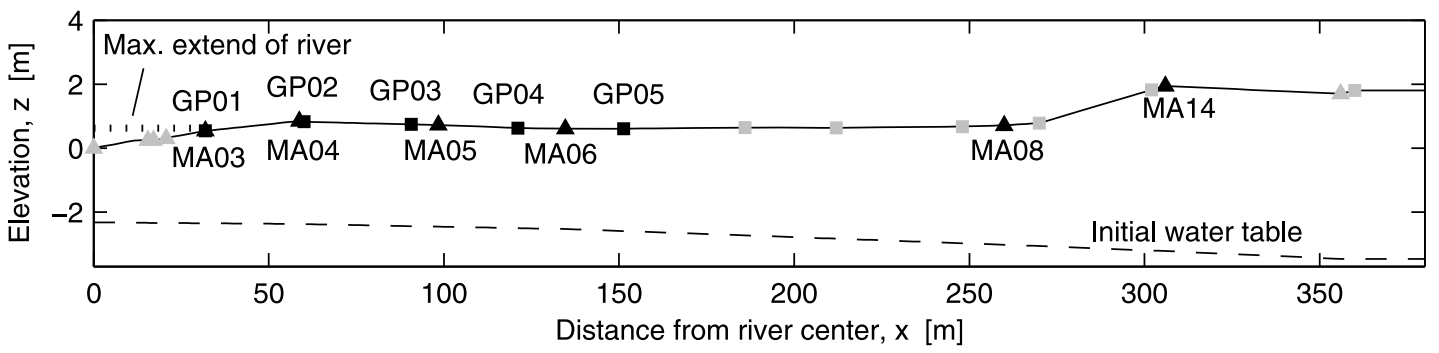

Figure 1. Cross section of transect 1 perpendicular to the river showing terrain, gravity stations (squares, labeled GPXX), boreholes (triangles, labeled MAYY), initial water table, and the maximum extent of the river. Black symbols and labels denote points from which data were used; gray points were not used.

with fully screened PVC pipes. Dug-up material was used to fill the space around the pipe. The borehole was completed with a concrete cap with a metal screw top. Heads were measured using an audio signal dipper with an error of $0.02 \mathrm{~m}$. Boreholes were labeled MA01 through MA11. Only the six boreholes shown in Figure 1 were used in the calibration. The rest were either flooded immediately when the river began to rise or were difficult to model because of the speed of change close to the river. A fifth discarded borehole was located $360 \mathrm{~m}$ away from the river. Upon model start, it consistently showed a shift in water table of some centimeters within the first few time steps. The precise reason for this is not known, but we assume that it is either because of model boundary effect or because the initial water table in this part of the model is not sufficiently described through only two boreholes. The effect of removing data from this one borehole is expected to be only minor since (1) there are six other boreholes along the transect, (2) the discarded borehole is located at the least dynamic end of the model domain, and (3) borehole MA14 and the discarded borehole show the same ET prior to the flood arrival. MA14 can thus be taken to represent the ET far away from the river. Figure 2 shows the head data collected at the site.

[15] The river stage was measured using a gauge with centimeter markings. During the first 7 days, the level rose quickly from a water table below surface up to $0.37 \mathrm{~m}$, from which it rose more gradually to $0.62 \mathrm{~m}$ over the subsequent
31 days. The width of the river was measured and is shown in Figure 1. The maximum half width of the river at the end of the campaign was $34.7 \mathrm{~m}$.

\subsubsection{Gravity Measurements}

[16] Changes in gravity were measured using a Scintrex CG-5 relative gravity meter, which has a sensitivity of $1 \mu \mathrm{Gal}$ $\left(10^{-8} \mathrm{~m} \mathrm{~s}^{-2}\right)$ and a reported (case dependent) accuracy of 0.4 $3 \mu \mathrm{Gal}$ under good conditions [Merlet et al., 2008; Jacob et al., 2009; Christiansen et al., 2011]. We used the methodology for data collection and treatment as described by Christiansen et al. [2011]. The CG-5 gravimeter (serial number 40284) used in this paper was delivered from the manufacturer 5 months prior to the experiment. The instrument calibration was subsequently tested and confirmed on the Hanover calibration system, which consists of a set of stations with known gravity differences.

[17] Relative gravimeters have an inherent, time-varying drift and require a reference station relative to which the changes in gravity are measured [e.g., Torge, 1989]. We measured in a star network for high-precision data; that is, all measurements were made relative to one reference station and with a set of measurements being made to only one gravity station at a time [see, e.g., Torge, 1989, p. 251]. Eleven concrete platforms with the approximate size of a $10 \mathrm{~L}$ bucket were cast directly into the compact sand surface and named GP01 through GP11. This simple station design was very stable, and the platforms showed no signs of movement,
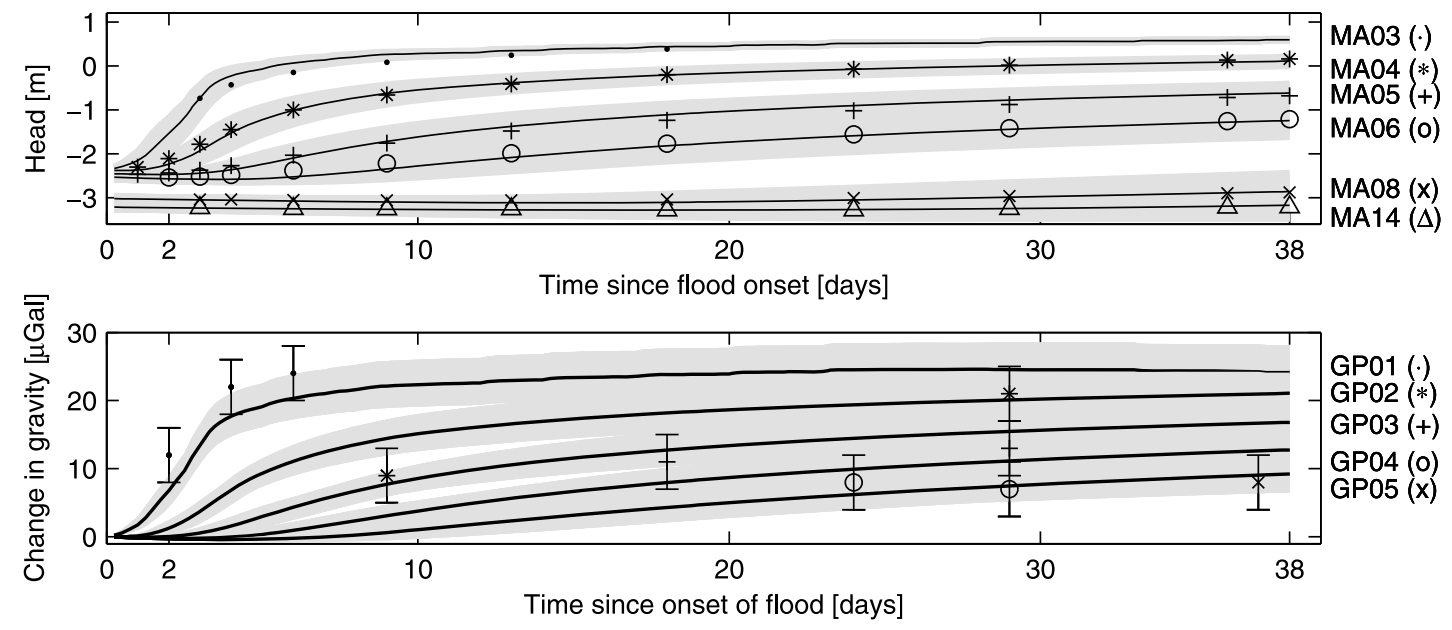

Figure 2. Calibration curves for best estimate (black) and the confidence limit intervals (gray). One standard deviation errors bars are shown for gravity data, but are too small to be visible for the head data. 
even when larger animals such as cows or elephants had stepped on them. Two additional reference stations were installed. One worked as the primary reference, the other as a backup to which the gravity difference was measured down to $1 \mu \mathrm{Gal}$ accuracy at campaign start. The backup was installed in case the primary reference got destroyed, but it was not required. The reference station was placed $450 \mathrm{~m}$ from the river, slightly offset from transect 1 . This distance was chosen as a trade-off between having a long distance to the flood event, avoiding a rise in water table at the reference station, and the need for manageable walking distances in the network. To estimate a suitable distance between the river and the reference station prior to establishing the gravity network, we used hydrological model results for a similar river bank in the Okavango Delta [Department of Water Affairs, 2004] and the observation that highly saline groundwater in the Okavango Delta is linked to stagnant water [Bauer et al., 2006b].

[18] With an assumed vertical gravitational gradient of $-3.086 \mu \mathrm{Gal} \mathrm{cm}{ }^{-1}$ [Torge, 1989, p. 324], the CG-5 sensitivity corresponds to a height change of $1 \mathrm{~cm}$. Variations in instrument height at the gravity stations were minimized by marking the position of the CG-5's tripod on the platform and by fixing the length of one of the tripod's legs. Instrument height was, in most cases, found to be within the measurement uncertainty of $1 \mathrm{~mm}$ between station occupations. The measured changes in the height of the concrete platforms were too small to result in a measurable change in gravity. Land surface elevation changes can also lead to a change in instrument height and can result from changes in air pressure [Caputo, 1962; Warburton and Goodkind, 1977] and head (pressure) changes in the confined aquifers. Under the present conditions, significant changes in air pressure are on a larger spatial scale than the area of investigation and thus uniformly affect both the reference station and the rest of the stations in the network so that any change in gravity cancels out. The contribution from positive air pressure changes is twofold: a decrease in gravity due to the upward attraction from the mass of the atmosphere and an increase in gravity due to the downward movement of the surface (this is in the case when a highpressure zone is traversing). The net effect is a decrease in gravity with higher air pressure. Following Pool [2008], a confined aquifer with storage coefficient of, say, 0.001 requires a $10 \mathrm{~m}$ head change in order to produce $1 \mathrm{~cm}$ of height change. The maximum observed head change in the lower aquifer was $0.48 \mathrm{~m}$, and any height change at the surface was therefore expected to be negligible.

[19] Handling the gravimeter affects measurement errors. After arrival at the field site, the CG-5 was left on the reference station for up to $1 \mathrm{~h}$ to allow the sensor spring to fully relax and the instrument to adjust to the ambient temperature. Between-station transport was by foot, which was found to be both faster and more gentle than transport by car through the rough terrain. During station occupation, the CG-5 was shaded from direct sunlight and shielded from the rare strong winds.

[20] The gravity difference $\delta g$ between the reference station and the station of interest was measured six times repeatedly per hour. The six data points were then corrected for tidal effects [Cartwright and Tayler, 1971; Cartwright and Edden, 1973] and a linear drift using the software GravAP [Schüler, 2008]. The instrument time was synchronized with GPS satellite time. Denoting the temporal change in gravity $\Delta g=\delta g_{t>0}-\delta g_{t=0}$, where time $t=0$ is the time of the baseline measurement before flood arrival, we obtained an accumulated accuracy of $\sigma_{\Delta g}=4 \mu \mathrm{Gal}$ on the change in gravity. Only GP01 through GP05 showed significant changes in gravity relative to the base station, and so the remainder were not employed in the model calibration.

[21] The water in the flooded river itself constitutes a large added mass to the system. On the basis of the topography data, the gravitational pull attraction from the river at the station closest to the river, GP01, was estimated for the time just before the station itself was flooded. This was done by representing the river water by a number of parallelepipeds for which the gravitational pull was calculated using the prism formula of Leirião et al. [2009]. The error was calculated to be $<0.2 \mu \mathrm{Gal}$ and could be neglected. As shown by Llubes et al. [2004], gravity signals from hydrology at regional scales, such as the flooding of the remaining delta, are below detection level because of the distance and the near $90^{\circ}$ angle to vertical of the changes. Furthermore, any global-scale hydrological signal cancels out in the star network.

\subsection{Analytical Investigation}

[22] An analytical model of riverbank infiltration is presented that illustrates the effect of the groundwater storage on the gravity data during a calibration. The water table as a function of time and space can be computed analytically under a number of simplifying assumptions.

[23] 1. The groundwater level varies only in one spatial dimension, $x$. The $x$ coordinate direction is perpendicular to the river.

[24] 2. The aquifer hydraulic conductivity is homogeneous and the riverbed hydraulic conductivity is equal to the aquifer hydraulic conductivity. This is justified on the basis of the soil samples taken from the boreholes and the observation that the riverbed for the largest part consists of the same sand as the aquifer.

[25] 3. The time dependence of the water level in the river is a Heaviside step function.

[26] 4. The groundwater table prior to the arrival of the flood is uniform over the entire domain.

[27] 5. Evapotranspiration is negligible.

[28] Under these assumptions, the governing equation for the groundwater level $(h)$ reads

$$
S_{y} \frac{\partial h(x, t)}{\partial t}=T \frac{\partial^{2} h(x, t)}{\partial x^{2}},
$$

where $T\left(\mathrm{~m}^{2} \mathrm{~s}^{-1}\right)$ is the transmissivity $\left(T=K_{h} H\right.$, where $H$ is the aquifer thickness). The governing equation is subject to the boundary conditions

$$
\begin{gathered}
h(0, t)=u(t)\left(h_{b}-h_{0}\right)+h_{0} \\
h(\infty, t)=h_{0}
\end{gathered}
$$

and the initial condition

$$
h(x, 0)=h_{0},
$$

where $h_{0}$ is the uniform groundwater level prevailing throughout the domain prior to flood arrival and $h_{b}$ is the water level in the river after flood arrival. The symbol $u(t)$ 

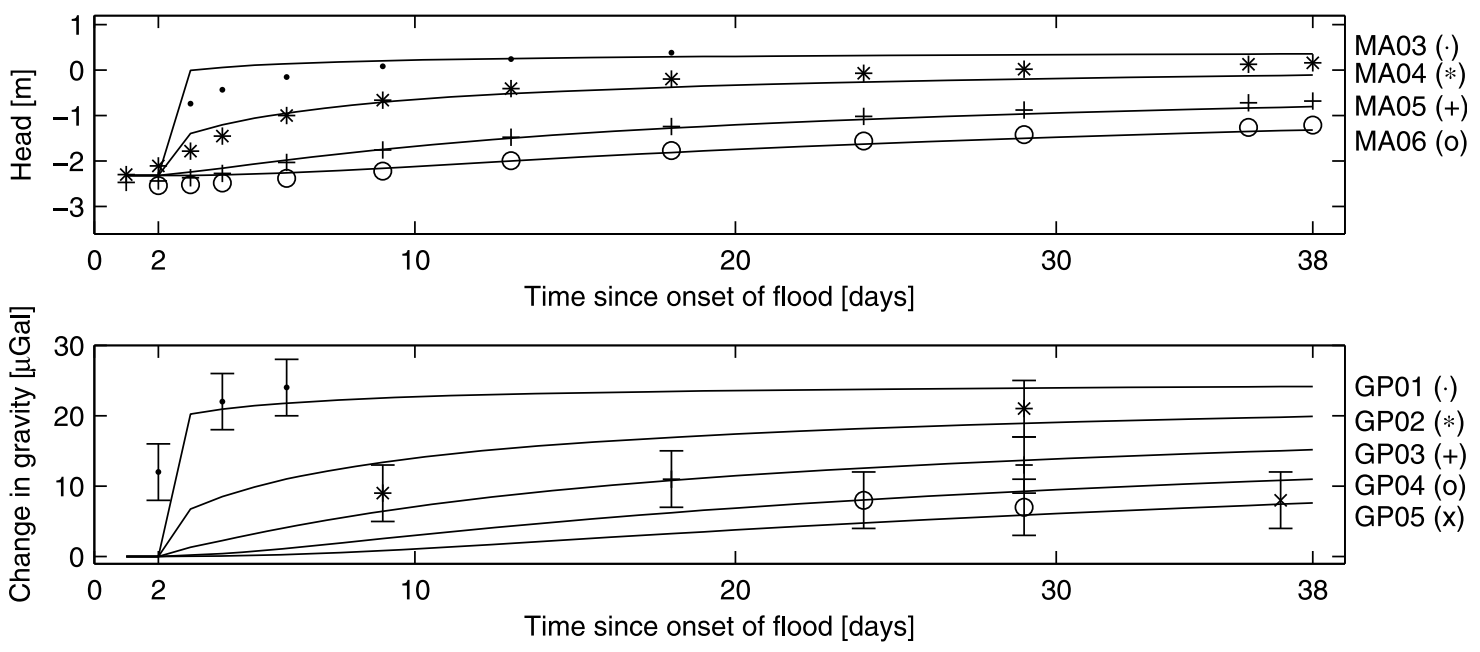

Figure 3. Comparison of the analytical model (lines) with field data for $S_{y}=0.23$ and $T=44 \mathrm{~m}^{2} \mathrm{~d}^{-1}$ (equivalent to $K_{h}=11 \mathrm{~m} \mathrm{~d}^{-1}$ for a $4 \mathrm{~m}$ thick aquifer). One standard deviation errors bars are shown for gravity data, but are too small to be visible for the head data.

denotes the Heaviside step function. The analytical solution to this problem reads

$$
h(x, t)=\left(h_{b}-h_{0}\right) \operatorname{erfc}\left(\sqrt{\frac{S_{y} x^{2}}{T 4 t}}\right)+h_{0},
$$

where erfe is the complementary error function. The corresponding change in gravity $\Delta g$ is

$$
\begin{aligned}
\Delta g= & \gamma \rho S_{y} \int_{-\infty}^{+\infty} \int_{-\infty}^{+\infty}\left\{\left[\left(x-x_{m}\right)^{2}+\left(y-y_{m}\right)^{2}+\left(h-z_{m}\right)^{2}\right]^{-1 / 2}\right. \\
& \left.-\left[\left(x-x_{m}\right)^{2}+\left(y-y_{m}\right)^{2}+\left(h_{0}-z_{m}\right)^{2}\right]^{-1 / 2}\right\} \mathrm{d} x \mathrm{~d} y
\end{aligned}
$$

where $\gamma=6.673 \times 10^{-11} \mathrm{~m}^{3} \mathrm{~kg}^{-1} \mathrm{~s}^{-2}$ is the gravitational constant and $\rho$ is the density of water. The subscript $m$ denotes the position at which gravity is measured. Figure 3 shows equations (5) and (6) plotted against field data. We see that the analytical solution is a good approximation for intermediate and late times (about day 12 and onward) and distances from the river. The two farthest boreholes (MA08 and MA14) were not included because of a strong ET signal. Equation (5) shows that the head is a function of the ratio of $S_{y}$ and $T$. We have, in other words, one function with two unknowns. When calibrating the model to head data, it is only possible to estimate the fraction $S_{y} / T$ even if head data are available at different locations. In a model calibration, the parameter correlation coefficient is 1 . This implies an infinite number of parameter combinations will fit equation (5) equally well to a given set of head measurements. In contrast, the gravity change quantified by equation (6) includes the same dependence on $S_{y} / T$ through the $h_{f}$ term, but $S_{y}$ also occurs independently of $T$. Thus, when equations (5) and (6) are simultaneously fitted to head and gravity data, the parameter correlation coefficient decreases. In the examples shown, it decreased to 0.96. Even a slight change from an (absolute) value of 1 will greatly improve the parameter estimate [Poeter and Hill, 1997].

\subsection{Calibration Based on Synthetic Data}

[29] In this section, synthetic head and gravity data are fit to a 1-D physically based, homogeneous numerical model, including ET and a horizontally expanding river with a gradual water level change. The model is tested to examine the sensitivity to changes in parameters and to benchmark the benefit of adding gravity to head data in the calibration process.

\subsubsection{Model Setup and Synthetic Data}

[30] Assuming symmetric groundwater flow away from the river, transect 1 was modeled in one dimension over a distance of $400 \mathrm{~m}$ from the river center with MODFLOW-96 [Harbaugh and McDonald, 1996]. The gravitational response to head changes can be calculated using the algorithm of Leirião et al. [2009]. The cross-section profile is shown in Figure 1. A $1 \mathrm{~m}$ horizontal discretization was employed for the first $36 \mathrm{~m}$, with a $2 \mathrm{~m}$ discretization thereafter. The calculation of gravity was three-dimensional and the $y$ dimension was set "sufficiently large" to $500 \mathrm{~m}$ ( $\pm 250 \mathrm{~m}$ from the transect 1 installations) to yield negligible truncation errors. The river was modeled as growing both in level and width in 17 steps according to field data. The model employed a uniform $C_{r}$ defined as $K_{r} A / L$, where $K_{r}$ is the hydraulic conductivity of the riverbed, $L$ is the thickness of the riverbed, and $A$ is the area of the river cell. This is a convenient definition since, often, only $A$ is known. $K_{h}, S y$, $C_{r}$, and ET were all uniform in space and time. The latter is supported by head data recorded over 46 days prior to the flood event. They show only a small difference in ET from $1.5 \mathrm{~mm} \mathrm{~d}^{-1}$ close to the river to $1.1 \mathrm{~mm} \mathrm{~d}^{-1}$ the farthest away from the river (assuming $S_{y}=0.21$ ). The parameters were set as shown in Table 1.

[31] The synthetic data set consists of head and gravity data for the same positions (Figure 1) and times as the field data. Random, normally distributed noise was added to both data sets with a standard deviation of $0.04 \mathrm{~m}$ for head and $4 \mu \mathrm{Gal}$ for gravity to replicate errors in the field data.

\subsubsection{Sensitivity Analysis}

[32] For a data type to provide a constraint on a model parameter, the data (observation) must be sensitive to changes in the parameter. We define the absolute sensitivity 
Table 1. Parameters on Which the Synthetic Data Were Based ${ }^{\mathrm{a}}$

\begin{tabular}{lccc}
\hline Parameter & Synthetic Data & Lower Bound & Upper Bound \\
\hline$K_{h}\left(\mathrm{~m} \mathrm{~d}^{-1}\right)$ & 10 & 0.001 & 1000 \\
$S_{y}\left(\mathrm{~m}^{2} \mathrm{~d}^{-1}\right)$ & 0.25 & 0.01 & 0.5 \\
$C_{r}$ & 5000 & 5 & 500,000 \\
ET $\left(\mathrm{m} \mathrm{d}^{-1}\right)$ & 0.002 & 0.0001 & 0.01 \\
\hline
\end{tabular}

${ }^{\mathrm{a}}$ The lower and upper bounds were applied during the model calibration.

(as) as the change from the baseline observation due to a $5 \%$ change in one parameter. The sensitivity varies both in space and time, and Figure 4 shows absolute sensitivity at two selected boreholes and gravity stations. In Figure 4, GP02 and MA04 are close to the river, GP04 is at an intermediate distance, and MA08 is the farthest away. Figure 4 shows a large sensitivity to $K_{h}$ and $S_{y}$ at early times. The curves for GP02 indicate that gravity data are particularly useful for constraining $S_{y}$. Sensitivity to ET is largest at late times when the flood-induced groundwater wave has not yet reached the borehole or gravity station or has only resulted in a small head change. All four observations are close to being insensitive to changes in $C_{r}$, and so this parameter is difficult to determine during calibration.

\subsubsection{Objective Function and Data Weighting}

[33] Model calibration was conducted using PEST [Doherty, 2010], which employs a gradient search method to minimize the objective function $\Phi$ :

$$
\begin{gathered}
\Phi_{\text {total }}=(1-w) \Phi_{h}+w \Phi_{\Delta g}, \\
\Phi_{h}=\left(n_{h} \sigma_{h}^{2}\right)^{-1} \sum_{i=1}^{n_{h}}\left(h_{\mathrm{obs}, i}-h_{\mathrm{sim}, i}\right)^{2}, \\
\Phi_{\Delta g}=\left(n_{\Delta g} \sigma_{\Delta g}^{2}\right)^{-1} \sum_{i=1}^{n_{\Delta g}}\left(\Delta g_{\mathrm{obs}, i}-\Delta g_{\mathrm{sim}, i}\right)^{2},
\end{gathered}
$$

where $w$ is a weight parameter, $n$ is the number of observations, $\sigma$ is the data uncertainty, $h$ is head, $\Delta g$ is gravity, and the subscripts obs and sim indicate observation and simulation, respectively. By letting $w$ increase stepwise from 0 to 1 , the relative weight on head versus gravity data was increased from full weight on head data only to full weight on gravity data only. Note that in equations (8) and (9), $\Phi_{h}$ and $\Phi_{\Delta g}$ are normalized by the variance of the observations so that $w=0.5$ corresponds to equal weighting of head and gravity data.

\subsubsection{Estimation of Two Parameters}

[34] Using the synthetic data, $K_{h}$ and $S_{y}$ were calibrated in the transect 1 model, with $w$ varying from 0 to 1 in 100 steps. To avoid dependencies of the solution on the start point in parameter space, three random parameters sets were drawn within the parameters bounds (see Table 1) for each $w$, so that 303 calibration attempts were required in total. Parameter limits were set broadly, so they did not constrain the solution.

[35] To study the effect of a varying $w$, four different criterion were examined. The first was a Pareto front of the normalized root-mean-square errors defined as $\mathrm{NRMSE}_{h}=$ $\sqrt{\Phi_{h}}$ and $\mathrm{NRMSE}_{\Delta g}=\sqrt{\Phi_{\Delta_{g}}}$, respectively (Figure 5a). The
Pareto front illustrates the trade-off between the model's ability to fit two different data sets at the same time when varying the relative weights on the data sets. The points form a well-defined front, which shows that the calibration algorithm is good at finding optimal solutions. No solutions off the front are found. We also see that most of the solutions are close together, with outliers occurring only when a large weight is put on gravity data.

[36] The estimated parameter values and their $95 \%$ confidence intervals are shown in Figures $5 \mathrm{~b}$ and $5 \mathrm{c}$ as a function of $w$. We note four things.

[37] 1. The parameter values are close to the true values and show very little variation, except when (almost) no weight is given to head data.

[38] 2. For $w$ close to 1, the parameter uncertainties grow considerably. The confidence intervals are a measure of how well constrained the parameter value is. But they must be
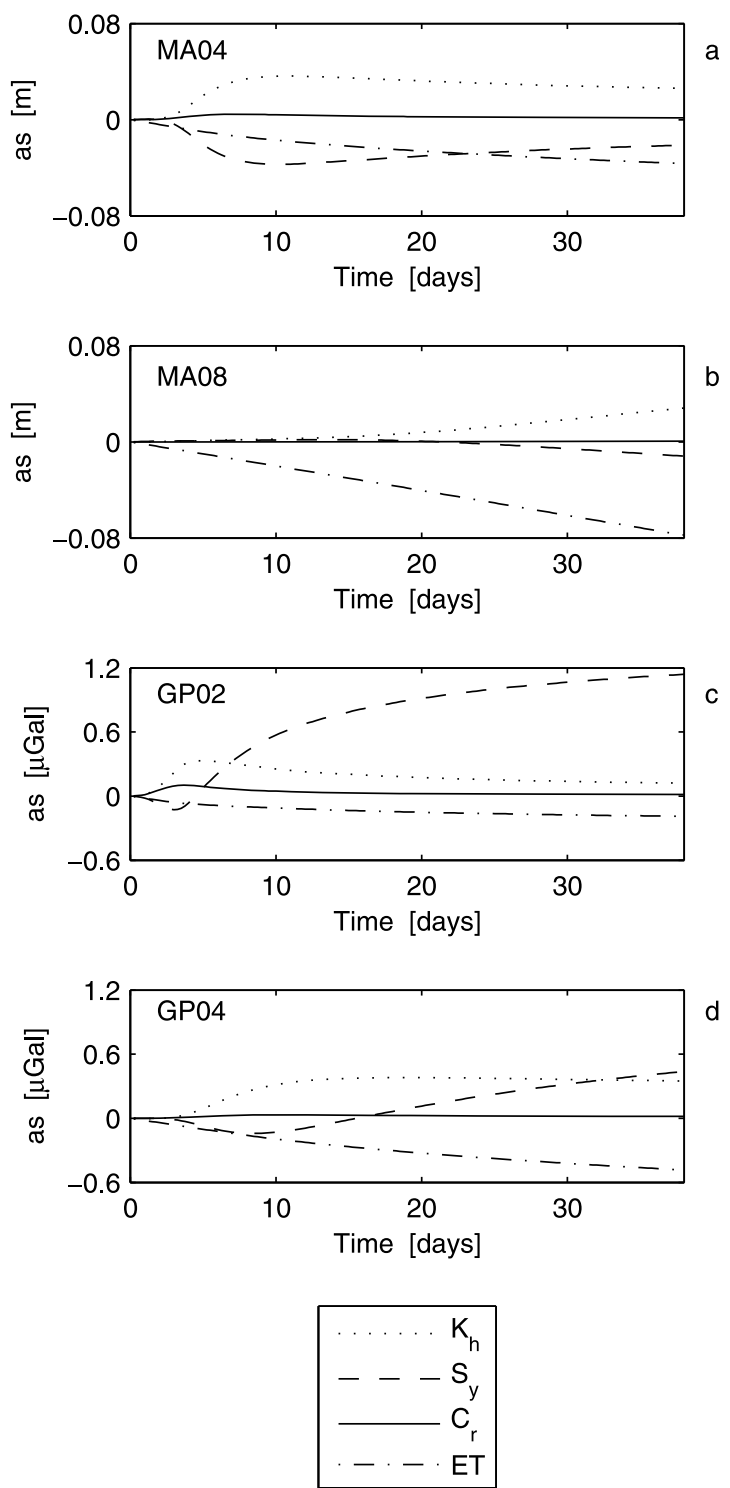

Figure 4. Absolute sensitivities (as) for gravity (GP02 and GP04) and head (MA04 and MA08) observations. Parameters were in turn varied $+5 \%$ from the baseline values. 

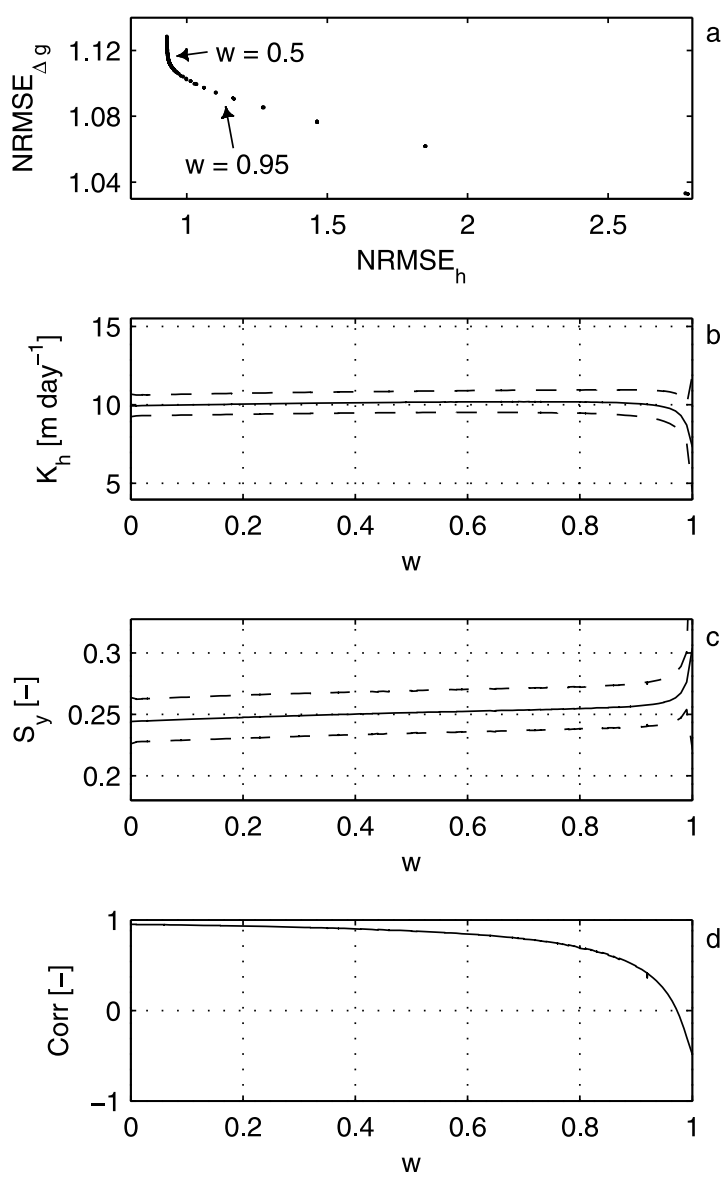

Figure 5. Calibration results for synthetic data with varying $w$. (a) Pareto front. (b) $K_{h}$ (solid line) and 95\% confidence intervals (dashed line). True value is $K_{h}=10 \mathrm{md}^{-1}$. (c) $S_{y}$ (solid line) and 95\% confidence intervals (dashed lines). True value is $S_{y}=0.25$. (d) Parameter correlation coefficient. For Figures $5 b$ and $5 c$, the axes are equal to those on Figure 6 better comparison.

used with care because of the assumption of linearity around the parameter value, which is not fully valid.

[39] 3. Even for $w=0$ (only head data used), parameters are estimated with a small confidence interval. This contradicts the analysis of the analytical model but simply shows that the analytical model does not represent the full dynamics of the system. If the river level rise and the horizontal extension of the river are considered to be a combination of individual steps, i.e., a linear combination of equation (5) with different but known sets of $\left(h_{0}, h_{b}\right)$ and known location of the river edge, the inverse analytical problem becomes overdetermined for three or more $\left(h_{0}, h_{b}\right)$ sets.

[40] 4. As more weight is given to gravity data, $S_{y}$ becomes better constrained (though the absolute change in the interval is small) up to a value of $w$ close to 1 . This illustrates the potential for gravity data to provide information on this important model parameter (recall GP02 in Figure 4). It is notable that gravity data alone do not provide a good constraint on the parameters.

[41] The last criteria on model fit examined is the parameter correlation coefficient (Figure 5d). The coefficient starts at
0.97 and rapidly drops off to -0.60 close to $w=1$. Even though the absolute correlation coefficient is lowest for $w=1$, gravity data alone do not constrain the parameters better than head data alone, as already demonstrated.

\section{Results}

[42] The analysis of synthetic data provides an understanding of the effect gravity data have on the parameter estimation without structural errors present in the model and with perfect knowledge of the data noise distribution. Structural errors arise from the imperfect model geometry, assumptions of a homogeneous soil, and the stepwise (instead of continuous) rise of the river. To account for the added uncertainty in the parameter estimation, we have increased the uncertainty on head data to $0.04 \mathrm{~m}$. Head measurements are precise point measurements, and so model output is sensitive to model structural errors and differences between model and actual data acquisition time. In contrast, gravity observations average over a large volume and so are less sensitive to these types of errors.

[43] The calibration results for the field data are presented in sections 3.1 and 3.2. We first fix the values for $C_{r}$ and ET for better comparison with the synthetic data analysis.
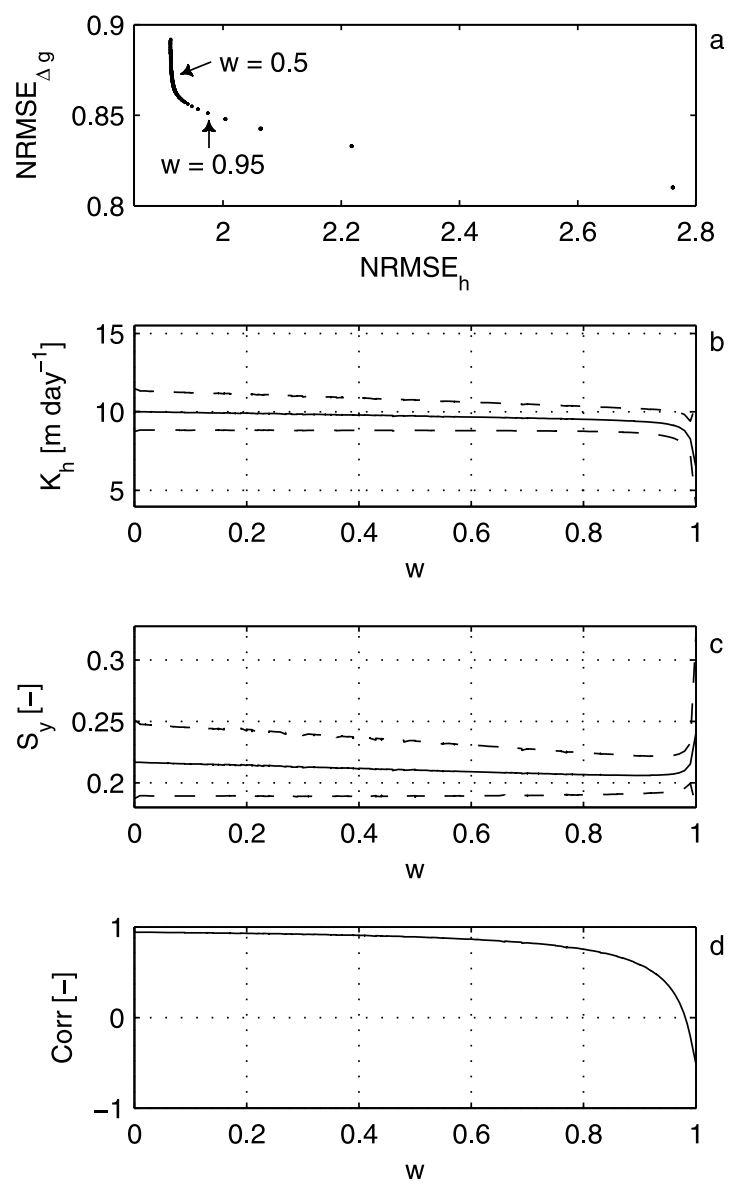

Figure 6. Calibration results for field data with varying $w$ and two free parameters. (a) Pareto front. (b) $K_{h}$ (solid line) and 95\% confidence intervals (dashed lines). (c) $S_{y}$ (solid line) and 95\% confidence intervals (dashed lines). (d) Parameter correlation coefficient. 


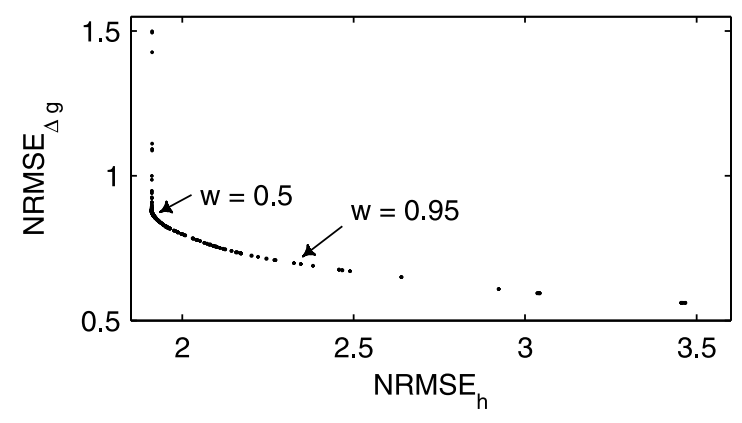

Figure 7. Pareto front for field data with four free parameters: $K_{h}, S_{y}, C_{r}$, and ET.

\subsection{Field Data: Two Free Parameters}

[44] We set $C_{r}=4500 \mathrm{~m}^{2} \mathrm{~d}^{-1}$ and ET $=0.002 \mathrm{~m} \mathrm{~d}^{-1}$, anticipating the results from four free parameters in section 3.2, and assume perfect knowledge of these two parameters. The Pareto front (Figure 6a) and the parameter correlation coefficient (Figure 6d) show similar behavior to that observed for the synthetic case. The estimated parameters, $K_{h}$ and $S_{y}$ (Figures $6 \mathrm{~b}$ and $6 \mathrm{c}$ ), show only slight changes with $w$, unless $w$ is close to 1 . The confidence intervals are larger than for the
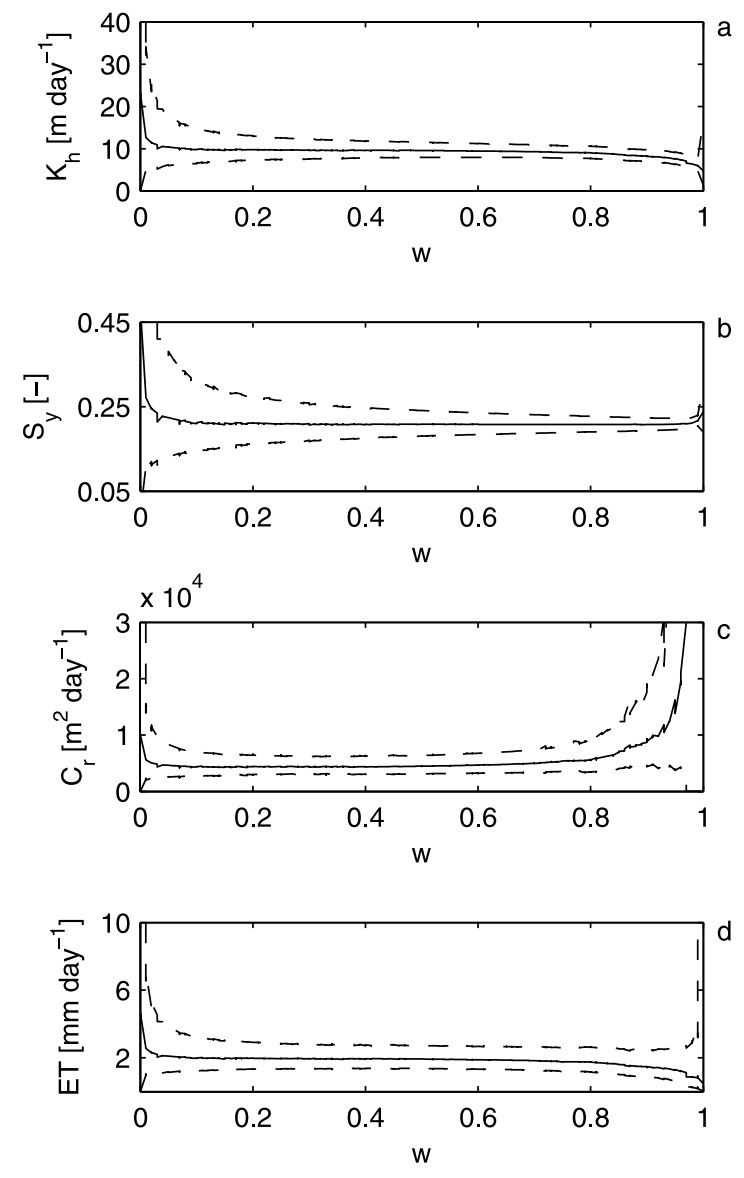

Figure 8. Parameter values as a function of $w$. All parameters are undetermined for $w=0$. The same is true for $C_{r}$ and ET when $w=1 . C_{r}$ has a final value of $500,000 \mathrm{~m}^{2} \mathrm{~d}^{-1}$, which was its upper limit in the calibration routine. The parameter axes are cut below maximum values to better show the curves.

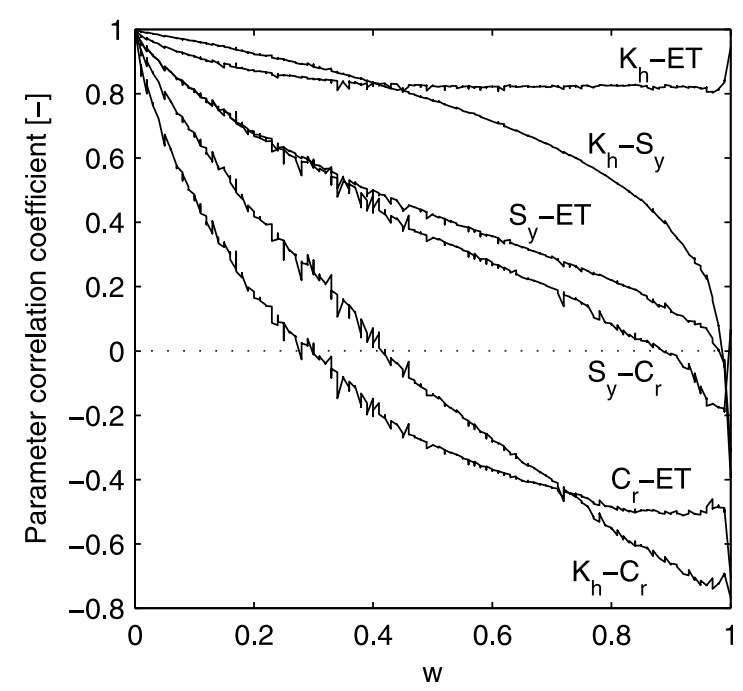

Figure 9. Parameter correlation coefficients as a function of $w$.

synthetic case, which reflects structural noise in the model and is possibly due to a different data noise distribution than the assumed Gaussian. Still, the parameters are well constrained, also when $w=0$, and the confidence intervals generally diminish with increasing $w$.

\subsection{Field Data: Four Free Parameters}

[45] Up to this point, the analysis has considered only two calibration parameters. In the real-world case, neither ET and $C_{r}$ were known. Both gravity and head data are sensitive to changes in ET and $C_{r}$, but less to the latter, so we included the two extra parameters in the calibration, thereby increasing the degrees of freedom to four. Increasing the number of free parameters led to a better data fit but also to larger parameter uncertainties.

[46] The Pareto front (Figure 7) is similar to that of the two-parameter cases considered previously, but with a very distinct change in slope at $w=0.5$. The solutions rapidly converge to the vicinity of this point as $w$ increases. If the conceptual model is assumed to be a good representation riverbank infiltration, the NRMSE values for $\Delta g$ suggest that the overall data uncertainty is correctly estimated, with a tendency to be a little high. For $h$ we see values close to 2 , which indicates that the data uncertainty was underestimated.

[47] The confidence limits of each parameter are narrow, and there is little to no variation of the confidence intervals over a large range of $w$ (Figure 8). At $w=0$, the confidence intervals show that all the parameters are undetermined. Comparing the confidence interval for $K_{h}$ and $S_{y}$ in Figures 6 and 8 at $w=1$, we see that the two parameters are better constrained in the four-parameter case. In Figure 6, perfect (but probably also incorrect) knowledge of $C_{r}$ and ET was assumed, and any parameter uncertainty had to be assigned to $K_{h}$ and $S_{y}$. In Figure 8 a large uncertainty is assigned to both $C_{r}$ and $\mathrm{ET}$ for $w=1$, and thus less uncertainty is assigned to $K_{h}$ and $S_{y}$.

[48] Four free parameters result in six parameter correlation coefficients (Figure 9). All coefficients are 1 at $w=0$, which explains why the parameters have close to infinite uncertainty bounds in this situation. An infinite number of 


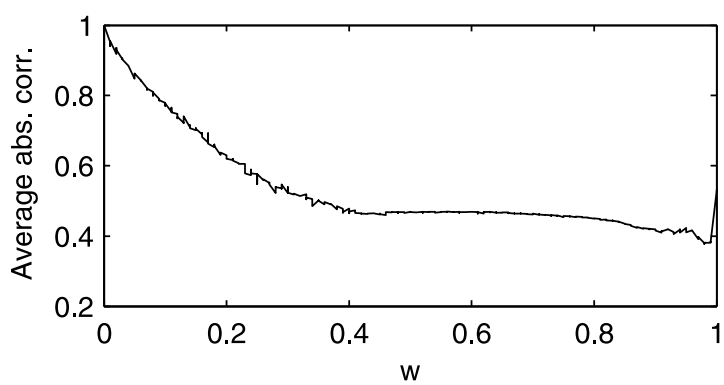

Figure 10. Average absolute parameter correlation coefficients as a function of $w$.

parameter sets will fit the data equally well. Giving weight to gravity data gradually lowers the absolute value of the coefficients, but there is no "best" value of $w$ that allows the simultaneous minimization of the magnitude of all correlation coefficients. For $w=1$, all absolute coefficient values are different from 1 . The highest value is for $K_{h}$-ET, which reaches 0.9448 . Figure 10 shows the average absolute parameter correlation coefficients. It gives a picture of the overall change in correlation coefficients and shows only a small variation for $0.4<w<0.8$.

[49] On the basis of the analysis of Figures 7-10, $w=0.5$ is selected for the determination of the calibration results shown in Table 2. To estimate the model prediction uncertainty, we ran the model with the $4^{2}=16$ combinations of parameters given by the individual $95 \%$ parameter confidence limits. Because of the nonlinearity of the model, this produces confidence limits that are likely to be larger than the 95\% interval. The calibration curves (Figure 2) show good agreement between field data and the model for both head and gravity data. Furthermore, we see that the $95 \%$ confidence limits and the error bounds (one standard deviation) overlap in all cases. The difficulties in modeling the dynamics of the river are reflected in MA03 and GP01, which show poorer fits compared to the other data.

\section{Discussion}

[50] The choice of conceptual model, the model geometry, parametrization, and forcing (e.g., temporal and spatial behavior of the river) are crucial for the calibration values of the model parameters. We chose a 1-D physically based, numerical model with homogeneous parameters to represent the hydrological system under investigation. The 1-D assumption implied two choices: (1) no leakage to the lower aquifer and (2) ignoring anisotropy. For choice 1, we know from a deep borehole close to transect 1 (BH8274) that this is not correct. A measured delayed and attenuated rise in head at screen depth showed increased water storage in the lower aquifer. Confined aquifers do not contribute to the measur-

Table 2. Estimated Parameters With 95\% Confidence Limits for $w=0.5$

\begin{tabular}{lccc}
\hline Parameter & Calibration Results & Lower Limit & Upper Limit \\
\hline$K_{h}\left(\mathrm{~m} \mathrm{~d}^{-1}\right)$ & 9.58 & 7.96 & 11.54 \\
$S_{y}$ & 0.21 & 0.18 & 0.24 \\
$C_{r}\left(\mathrm{~m}^{2} \mathrm{~d}^{-1}\right)$ & 4464 & 3118 & 6390 \\
$\mathrm{ET}\left(\mathrm{m} \mathrm{d}^{-1}\right)$ & 0.0019 & 0.0014 & 0.0027 \\
\hline
\end{tabular}

able change in gravity [e.g., Pool, 2008], so the modeled gravity does not underestimate the change in gravity. To test the validity of choice 2 , models with two to eight layers and $K_{h \text {,vertical }} / K_{h \text {,horizontal }}=1 / 10$ anisotropy were calibrated. This leads to slightly different parameter values (e.g., a higher $S_{y}$ ), but model results did not fit data as well as for the 1-D model. As as result and following the principle of parsimony, the 1-D model was chosen above multilayer models.

[51] For the boreholes closest to the river, the rise in groundwater table approximates a Bouguer slab at late times. The change in gravity due to a change in water table $\Delta h$ is then given as $\Delta g=41.9 \mu \mathrm{Gal} \mathrm{m}^{-1} \Delta h S_{y}$ [e.g., Bonatz, 1967; Torge, 1989; Leirião et al., 2009]. This results in $S_{y}=$ $0.25 \pm 0.04$ (MA03 and GP01) and $S_{y}=0.21 \pm 0.04(\mathrm{MA04}$ and GP02). The values are in good agreement with the calibration result (Table 2). As discussed in detail by Montgomery [1971], changes in tilted water surfaces generally lead to an underestimated $S_{y}$. Using the Bouguer slab assumption on the present system gave falling $S_{y}$ values with distance (see Table 3), which is not supported by the soil samples taken from the boreholes. This demonstrated that the Bouguer slab assumption is inadequate for the full model area and justified the use of a computationally more complex approach.

[52] Despite the tendency in the literature to adopt parameter values from other models (e.g., for similar soil types), any estimated model parameter is strictly only valid for the model and data for which it was estimated. Nevertheless, for physically based models, the parameters $K_{h}, S_{y}$, and ET should be similar for models of other areas with similar geology and forcings. Studies on comparable sites in the Okavango Delta have found $K_{h}=4.5-19.68 \mathrm{~m} \mathrm{~d}^{-1}$ (slug tests) and ET $=2 \mathrm{~mm} \mathrm{~d}^{-1}$ (calibrated) [Wolski and Savenije, 2006] and $K_{h}=0.158 \mathrm{~m} \mathrm{~d}^{-1}$ (on average), $S_{y}=$ 0.2 , and $\mathrm{ET}=0.06-4.3 \mathrm{~mm} \mathrm{~d}^{-1}$ (calculated) [Bauer et al., 2004]; Class A pan evaporation, which constitutes an upper bound for the possible ET, has a minimum of 3-3.3 mm $\mathrm{d}^{-1}$ in June/July and a maximum in October of $8.3 \mathrm{~mm} \mathrm{~d}^{-1}$ [Ramberg et al., 2006]. These numbers generally correspond well with our results. The range of hydraulic conductivities is broad, but the parameter can vary by several orders of magnitude, and some variation is to be expected when investigating different locations, even when they have an apparently similar geology.

[53] Our results on the improved estimation of $S_{y}$ are similar to those reported by Blainey et al. [2007], who demonstrated the use of time-lapse gravity data in a synthetic pumping test. They also observed that gravity data alone do not constrain $K_{h}$ and $S_{y}$ well (knowledge of the initial water table is, in any case, needed to calculate the

Table 3. Average $S_{y}$ Estimates at Gravity Stations Using the Bouguer Slab Assumption ${ }^{\mathrm{a}}$

\begin{tabular}{ccc}
\hline Gravity Station & $S_{y}$ & Boreholes \\
\hline GP01 & $0.27 \pm 0.04$ & MA03 \\
GP02 & $0.24 \pm 0.03$ & MA04 \\
GP03 & $0.21 \pm 0.04$ & MA05 \\
GP04 & $0.14 \pm 0.05$ & average of MA05 and MA06 \\
GP05 & $0.15 \pm 0.07$ & MA06 \\
\hline
\end{tabular}

${ }^{\mathrm{a}}$ Where a gravity station was not colocated with a borehole, changes in head at the nearest borehole(s) were used. 
gravity change, so boreholes must be present). In principle, the demonstrated improvement of parameter estimation is not limited to these two types of hydrological settings, though the specific choice of conceptual model and parametrization plays an important role. As argued by Christiansen et al. [2011] in more detail, hydrogravity measurements are best suited for (but not exclusively) sandy soils, large variations in water storage, water table rise (as opposed to lowering), little or no precipitation, rapid storage variations, flat or gently sloping areas, and homogeneous soils. It must be taken into account that the application depends on the type of gravimeter available for the measurements and the conditions in the area of investigation (how rough the terrain is, how large an area needs to be surveyed, etc.). Suggested applications of coupled hydrogeophysical inversion with gravity data are pumping tests, riverbank storage (natural variations and variations due to dam regulation), water injection (for storage), and monitoring of ET in areas with a thick unsaturated zone and wet and dry seasons. The current Gravity and Hydrology in Africa (GHYRAF) project in southwest Niger exploits time-lapse gravity in relation to infiltration from a large rainwater pool [Pfeffer et al., 2009; Hinderer et al., 2009; Pfeffer et al., 2011].

[54] Collecting time-lapse relative gravity at the $\mu \mathrm{Gal}$ scale can be tedious and requires extra time, money, and training. In the present case, gravity measurements, in principle, replaced slug or pumping tests for $S_{y}$, pan evaporation measurements for $\mathrm{ET}$, and infiltrometers for $C_{r}$ estimation. An important limitation of hydrogravimetric data is that it only contains information on the unconfined aquifer. Slug and pumping tests do not have this limitation.

[55] The change in water table induced only a small gravity signal (up to $24 \mu \mathrm{Gal}$ ) compared to the instrument sensitivity and accuracy. A potential major error source in relative gravimetry is the instability of the reference station. In the present case, the water table below the reference point was monitored and showed less than $2 \mathrm{~cm}$ variation, which for $S_{y}=0.21$, corresponds to less than $0.18 \mu \mathrm{Gal}$. The station showed no signs of movement, and any change in gravity due to, e.g., air pressure changes was at sufficiently large scale to also affect the other measurement stations and thus canceled out. The last rainfall event took place more than 2 months before the gravity baseline was measured. For the $5 \mathrm{~m}$ thick, sandy unsaturated zone, the change in soil water over the duration of the experiment is assumed to be negligible.

\section{Conclusion}

[56] We measured changes in groundwater table and gravity during a riverbank infiltration event in the Okavango Delta. The data show a clear correspondence between change in water content and change in gravity. Through a simple analytical model, the ability of time-lapse gravity data to reduce the correlation between $K_{h}$ and $S_{y}$ was demonstrated. A more complex 1-D numerical model was calibrated for $K_{h}$ and $S_{y}$ and subsequently for $K_{h}, S_{y}, \mathrm{ET}$, and $C_{r}$, and the influence of gravity data on parameter uncertainties was investigated.

[57] Sensitivity analysis shows that gravity is sensitive to changes in all four parameters, with a particularly large sensitivity to $S_{y}$. We have shown that time-lapse gravity data can constrain model parameters through a coupled hydro- geophysical inversion. It is particularly useful for determining $K_{h}$ and $S_{y}$, but it is also of benefit when determining ET and $C_{r}$. The benefits of employing gravity data in hydrogeophysical inversion have never before been demonstrated on field data. The largest improvement was shown when four free parameters were estimated. With head data alone, the parameter uncertainty is close to infinity, and the four parameters cannot be determined. Gravity data alone does not constrain the model well either, but the combination of the two data types greatly improves parameter optimization.

[58] Increasing the weight on gravity data in the calibration gradually lowers the parameter uncertainties up to a parameter specific point. The choice of weight factor $w$ was found not to be of great importance, but results indicate that a value of $w=0.5$ is a good choice. This corresponds to weighting equally the information content in head and gravity data. The methodology used to analyze the parameter dependence on $w$ can easily be adopted for other models.

[59] Acknowledgments. We would like to thank the Department of Water Affairs and the Department of Geological Survey, Ministry of Minerals, Energy and Water Resources, Botswana, and Piotr Wolski from Harry Oppenheimer Okavango Research Centre, University of Botswana, for their assistance during the field campaign. We furthermore wish to thank Andrew Binley and two anonymous reviewers for their helpful comments on the manuscript. This work was funded by the Danish Agency for Science, Technology and Innovation under contract 274-06-0341.

\section{References}

Archie, G. (1942), The electrical resistivity log as an aid in determining some reservoir characteristics, Trans. Am. Inst. Min. Metall. Pet. Eng., $146,54-61$.

Bauer, P., G. Thabeng, F. Stauffer, and W. Kinzelbach (2004), Estimation of the evapotranspiration rate from diurnal groundwater level fluctuations in the Okavango Delta, Botswana, J. Hydrol., 288(3-4), 344-355, doi:10.1016/j.jhydrol.2003.10.011.

Bauer, P., R. Supper, S. Zimmermann, and W. Kinzelbach (2006a), Geoelectrical imaging of groundwater salinization in the Okavango Delta, Botswana, J. Appl. Geophys., 60(2), 126-141, doi:10.1016/j.jappgeo. 2006.01.003.

Bauer, P., R. Held, S. Zimmermann, F. Linn, and W. Kinzelbach (2006b), Coupled flow and salinity transport modelling in semi-arid environments: The Shashe River Valley, Botswana, J. Hydrol., 316(1-4), 163-183, doi:10.1016/j.jhydrol.2005.04.018.

Bauer-Gottwein, P., B. N. Gondwe, L. Christiansen, D. Herckenrath, L. Kgotlhang, and S. Zimmermann (2010), Hydrogeophysical exploration of three-dimensional salinity anomalies with the time-domain electromagnetic method (TDEM), J. Hydrol., 380(3-4), 318-329, doi:10.1016/j.jhydrol.2009.11.007

Blainey, J. B., T. P. A. Ferré, and J. T. Cordova (2007), Assessing the likely value of gravity and drawdown measurements to constrain estimates of hydraulic conductivity and specific yield during unconfined aquifer testing, Water Resour. Res., 43, W12408, doi:10.1029/ 2006WR005678

Bonatz, M. (1967), Der Gravitationseinfluß der Bodenfeuchte, Z. Vermessungswes., 92, 135-139.

Caputo, M. (1962), Tables for the deformation of an Earth model by surface mass distribution, J. Geophys. Res., 67(4), 1611-1616

Cartwright, D., and A. Edden (1973), Corrected tables of tidal harmonics, Geophys. J. R. Astron. Soc., 33(3), 253-264.

Cartwright, D., and R. Tayler (1971), New computations of tide-generating potential, Geophys. J. R. Astron. Soc., 23(1), 45-74.

Cassiani, G., A. Godio, S. Stocco, A. Villa, R. Deiana, P. Frattini, and M. Rossi (2009), Monitoring the hydrologic behaviour of a mountain slope via time-lapse electrical resistivity tomography, Near Surf. Geophys., 7(5-6), 475-486 
Chapman, D., E. Sahm, and P. Gettings (2008), Monitoring aquifer recharge using repeated high-precision gravity measurements: A pilot study in South Weber, Utah, Geophysics, 73(6), WA83-WA93.

Christiansen, L., S. Lund, O. B. Andersen, P. J. Binning, D. Rosbjerg, and P. Bauer-Gottwein (2011), Measuring gravity change caused by water storage variations: performance assessment under controlled conditions, J. Hydrol., 402, 60-70.

Creutzfeldt, B., A. Güntner, T. Klügel, and H. Wziontek (2008), Simulating the influence of water storage changes on the superconducting gravimeter of the Geodetic Observatory Wettzell, Germany, Geophysics, 73(6), WA95-WA104.

Crook, N., C. Welty, M. McGuire, and R. Knight (2008), An assessment of the use of the temporal microgravity technique to estimate the change in aquifer storage across the Gwynns Falls watershed, Eos Trans. $A G U$, 89(53), Fall Meet. Suppl., Abstract H51G-0944.

Damiata, B., and T. Lee (2006), Simulated gravitational response to hydraulic testing of unconfined aquifers, J. Hydrol., 318(1-4), 348-359.

Davis, K., Y. Li, and M. Batzle (2008), Time-lapse gravity monitoring: A systematic 4D approach with application to aquifer storage and recovery, Geophysics, 73(6), WA61-WA69.

Department of Water Affairs (2004), Maun Groundwater Development Project Phase 2, vol. 8, Recharge study, technical report, Minist. of Miner., Energy and Water Resour., Gaborone, Botswana.

Doherty, J. (2010), PEST: Model independent parameter estimation, Watermark Numer. Comput., Brisbane, Queensland, Australia.

Ferré, T., L. Bentley, A. Binley, N. Linde, A. Kemna, K. Singha, K. Holliger, J. A. Huisman, and B. Minsley (2009), Critical steps for the continuing advancement of hydrogeophysics, Eos Trans. AGU, 90(23), 200-201.

Gehman, C. L., D. L. Harry, W. E. Sanford, J. D. Stednick, and N. A. Beckman (2009), Estimating specific yield and storage change in an unconfined aquifer using temporal gravity surveys, Water Resour. Res., 45, W00D21, doi:10.1029/2007WR006096.

Gettings, P., D. Chapman, and R. Allis (2008), Techniques, analysis, and noise in a Salt Lake Valley 4D gravity experiment, Geophysics, 73(6), WA71-WA82.

Hagrey, S., and C. Müller (2000), GPR study of pore water content and salinity in sand, Geophys. Prospect., 48(1), 63-85.

Harbaugh, A., and M. McDonald (1996), User's documentation for MODFLOW-96, an update to the U.S. Geological Survey modular finite-difference ground-water flow model, U.S. Geol. Surv. Open File Rep., 96-485, 56 pp.

Hasan, S., P. Troch, P. Bogaart, and C. Kroner (2008), Evaluating catchment-scale hydrological modeling by means of terrestrial gravity observations, Water Resour. Res., 44, W08416, doi:10.1029/2007WR006321.

Hinderer, J., et al. (2009), The GHYRAF (Gravity and Hydrology in Africa) experiment: Description and first results, J. Geodyn., 48(3-5), 172-181, doi:10.1016/j.jog.2009.09.014.

Hinnell, A. C., T. P. A. Ferré, J. A. Vrugt, J. A. Huisman, S. Moysey, J. Rings, and M. B. Kowalsky (2010), Improved extraction of hydrologic information from geophysical data through coupled hydrogeophysical inversion, Water Resour. Res., 46, W00D40, doi:10.1029/ 2008WR007060.

Howle, J. F., S. P. Phillips, R. P. Denlinger, and L. F. Metzger (2003), Determination of specific yield and water-table changes using temporal microgravity surveys collected during the second injection, storage, and recovery test at Lancaster, Antelope Valley, California, November 1996 through April 1997, U.S. Geol. Surv. Water Resour. Invest. Rep., 03-4019, $36 \mathrm{pp}$.

Huisman, J., S. Hubbard, J. Redman, and A. Annan (2003), Measuring soil water content with ground penetrating radar: A review, Vadose Zone J., 2(4), 476-491.

Jacob, T., R. Bayer, J. Chery, H. Jourde, N. L. Moigne, J. P. Boy, J. Hinderer, B. Luck, and P. Brunet (2008), Absolute gravity monitoring of water storage variation in a karst aquifer on the Larzac Plateau (southern France), J. Hydrol., 359(1-2), 105-117.

Jacob, T., J. Chery, R. Bayer, N. Le Moigne, J.-P. Boy, P. Vernant, and F. Boudin (2009), Time-lapse surface to depth gravity measurements on a karst system reveal the dominant role of the epikarst as a water storage entity, Geophys. J. Int., 177(2), 347-360, doi:10.1111/j.1365-246X.2009.04118.x.

Knight, R. (2001), Ground penetrating radar for environmental applications, Annu. Rev. Earth Planet. Sci., 29, 229-255.

Kowalsky, M., S. Finsterle, and Y. Rubin (2004), Estimating flow parameter distributions using ground-penetrating radar and hydrological measurements during transient flow in the vadose zone, Adv. Water Resour., 27(6), 583-599, doi:10.1016/j.advwatres.2004.03.003.
Krause, P., M. Naujoks, M. Fink, and C. Kroner (2009), The impact of soil moisture changes on gravity residuals obtained with a superconducting gravimeter, J. Hydrol., 373(1-2), 151-163, doi:10.1016/j. jhydrol.2009.04.019.

Leirião, S., H. Xin, L. Christiansen, O. B. Andersen, and P. Bauer-Gottwein (2009), Calculation of the temporal gravity variation from spatially variable water storage change in soils and aquifers, J. Hydrol., 365(3-4), 302-309, doi:10.1016/j.jhydrol.2008.11.040.

Llubes, M., N. Florsch, J. Hinderer, L. Longuevergne, and M. Amalvict (2004), Local hydrology, the Global Geodynamics Project and CHAMP/GRACE perspective: Some case studies, J. Geodyn., 38(3-5), 355-374.

Looms, M., A. Binley, K. Jensen, L. Nielsen, and T. Hansen (2008a), Identifying unsaturated hydraulic parameters using an integrated data fusion approach on cross-borehole geophysical data, Vadose Zone J., 7(1), 238-248.

Looms, M., K. Jensen, A. Binley, and L. Nielsen (2008b), Monitoring unsaturated flow and transport using cross-borehole geophysical methods, Vadose Zone J., 7(1), 227-237.

Ma, R., C. Zheng, H. Prommer, J. Greskowiak, C. Liu, J. Zachara, and M. Rockhold (2010), A field-scale reactive transport model for U(VI) migration influenced by coupled multirate mass transfer and surface complexation reactions, Water Resour. Res., 46, W05509, doi:10.1029/ 2009WR008168.

Merlet, S., A. Kopaev, M. Diament, G. Geneves, A. Landragin, and F. P. Dos Santos (2008), Micro-gravity investigations for the LNE watt balance project, Metrologia, 45(3), 265-274, doi:10.1088/0026-1394/45/3/002.

Michot, D., Y. Benderitter, A. Dorigny, B. Nicoullaud, D. King, and A. Tabbagh (2003), Spatial and temporal monitoring of soil water content with an irrigated corn crop cover using surface electrical resistivity tomography, Water Resour. Res., 39(5), 1138, doi:10.1029/2002WR001581.

Milzow, C., L. Kgotlhang, P. Bauer-Gottwein, P. Meier, and W. Kinzelbach (2009), Regional review: The hydrology of the Okavango Delta, Botswana-Processes, data and modelling, Hydrogeol. J., 17(6), 1297-1328, doi:10.1007/s10040-009-0436-0.

Montgomery, E. (1971), Determination of coefficient of storage by use of gravity measurements, Ph.D. dissertation, Dep. of Geosci., Univ. of Ariz., Tucson.

Naujoks, M., C. Kroner, A. Weise, T. Jahr, P. Krause, and S. Eisner (2010), Evaluating local hydrological modelling by temporal gravity observations and a gravimetric three-dimensional model, Geophys. J. Int., 182(1), 233-249, doi:10.1111/j.1365-246X.2010.04615.x.

Pfeffer, J., M. Boucher, J. Hinderer, G. Favreau, J. Boy, C. de Linage, B. Luck, and M. Oi (2009), Annual water storage variability in southwest Niger: Confrontation of absolute gravimetric measurements and magnetic resonance soundings surveys with hydrological observations, Eos Trans. $A G U, 90(52)$, Fall Meet. Suppl., Abstract G43A-0717.

Pfeffer, J., M. Boucher, J. Hinderer, G. Favreau, J. P. Boy, C. de Linage, B. Cappelaere, B. Luck, M. Oi, and N. Le Moigne (2011), Local and global hydrological contributions to time-variable gravity in southwest Niger, Geophys. J. Int., 182(2), 661-672.

Poeter, E., and M. Hill (1997), Inverse models: A necessary next step in ground-water modeling, Ground Water, 35(2), 250-260.

Pool, D. (2008), The utility of gravity and water-level monitoring at alluvial aquifer wells in southern Arizona, Geophysics, 73(6), WA49-WA59.

Pool, D., and J. Eychaner (1995), Measurements of aquifer-storage change and specific yield using gravity surveys, Ground Water, 33(3), 425-432.

Ramberg, L., P. Wolski, and M. Krah (2006), Water balance and infiltration in a seasonal floodplain in the Okavango Delta, Botswana, Wetlands, 26(3), 677-690.

Reedy, R., and B. Scanlon (2003), Soil water content monitoring using electromagnetic induction, J. Geotech. Geoenviron. Eng., 129(11), 1028-1039, doi:10.1061/(ASCE)1090-0241(2003)129:11(1028).

Rings, J., J. A. Huisman, and H. Vereecken (2010), Coupled hydrogeophysical parameter estimation using a sequential Bayesian approach, Hydrol. Earth Syst. Sci., 14(3), 545-556.

Rucker, D., and T. Ferré (2004), Parameter estimation for soil hydraulic properties using zero-offset borehole radar: Analytical method, Soil Sci. Soc. Am. J., 68(5), 1560-1567.

Samouelian, A., I. Cousin, A. Tabbagh, A. Bruand, and G. Richard (2005), Electrical resistivity survey in soil science: A review, Soil Tillage Res., 83(2), 173-193, doi:10.1016/j.still.2004.10.004.

Schwartz, B. F., M. E. Schreiber, and T. Yan (2008), Quantifying fieldscale soil moisture using electrical resistivity imaging, J. Hydrol., 362(3-4), 234-246 
Schüler, T. (2008), GravAP: Gravimetric adjustment package, Inst. of Geod. and Nav., Univ. of the Fed. Armed Forces, Neubiberg, Germany. [Available at website http://www.ifen.unibw-muenchen.de/software/ gravap/index.html.]

Topp, G., J. Davis, and A. Annan (1980), Electromagnetic determination of soil-water content: Measurements in coaxial transmission lines, Water Resour. Res., 16(3), 574-582.

Torge, W. (1989), Gravimetry, vol. 1, Walter de Gruyter, Berlin.

Uhlenbrook, S., and J. Wenninger (2006), Identification of flow paths along hill slopes using electrical resistivity tomography (ERT), in Predictions in Ungauged Basins: Promise and Progress, edited by M. Sivapalan et al., IAHS Publ., 303, 15-20.

Warburton, R., and J. Goodkind (1977), Influence of barometric-pressure variations on gravity, Geophys. J. R. Astron. Soc., 48(3), 281-292.
Wolski, P., and H. Savenije (2006), Dynamics of floodplain-island groundwater flow in the Okavango Delta, Botswana, J. Hydrol., 320(3-4), 283-301, doi:10.1016/j.jhydrol.2005.07.027.

Zhou, Q., J. Shimada, and A. Sato (2001), Three-dimensional spatial and temporal monitoring of soil water content using electrical resistivity tomography, Water Resour. Res., 37(2), 273-285.

O. B. Andersen, DTU Space, Juliane Maries Vej 30, DK-2100 Copenhagen $\varnothing$, Denmark.

P. Bauer-Gottwein, P. J. Binning, L. Christiansen, and D. Rosbjerg, DTU Environment Miljøvej, Building 113, DK-2800 Kongens Lyngby, Denmark. (pbau@env.dtu.dk) 